\title{
Multiple insecticide resistance target sites in adult field strains of An. gambiae (s.l.) from southeastern Senegal
}

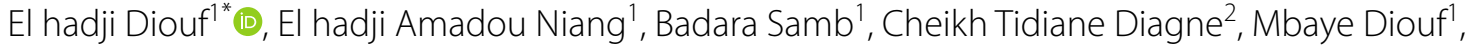
Abdoulaye Konaté ${ }^{\text {, Ibrahima Dia }}{ }^{2}$, Ousmane Faye ${ }^{1}$ and Lassana Konaté ${ }^{1}$

\begin{abstract}
Background: High coverage of long-lasting insecticidal nets (LLINs) and indoor residual spraying (IRS) are the cornerstones of vector control strategy in Senegal where insecticide resistance by the target vectors species is a great of concern. This study explores insecticide susceptibility profile and target-site mutations mechanisms within the Anopheles gambiae complex in southeastern Senegal.
\end{abstract}

Methods: Larvae of Anopheles spp. were collected in two sites from southeastern Senegal Kedougou and Wassadou/ Badi in October and November 2014, and reared until adult emergence. Wild $F_{0}$ adult mosquitoes were morphologically identified to species. Susceptibility of 3-5-day-old An. gambiae (s.l.) samples to 11 insecticides belonging to the four insecticide classes was assessed using the WHO insecticide susceptibility bioassays. Tested samples were identified using molecular techniques and insecticide resistance target-site mutations ( $k d r$, ace- 1 and $r d l)$ were determined.

Results: A total of 3742 An. gambiae (s.l.) were exposed to insecticides (2439 from Kedougou and 1303 from Wassadou-Badi). Tests with pyrethroid insecticides and DDT showed high level of resistance in both Kedougou and Wassadou/Badi. Resistance to pirimiphos-methyl and malathion was not detected while resistance to bendoicarb and fenitrothion was confirmed in Kedougou. Of the 745 specimens of An. gambiae (s.l.) genotyped, An. gambiae (s.s.) (71.6\%) was the predominant species, followed by An. arabiensis (21.7\%), An. coluzzii (6.3\%) and hybrids (An. gambiae (s.s.)/An. coluzzii; 0.4\%). All target site mutations investigated (Vgsc-1014F, Vgsc-1014S, Ace-1 and Rd) were found at different frequencies in the species of the Anopheles gambiae complex. Vgsc-1014F mutation was more frequent in $A n$. gambiae (s.s.) and An. coluzzii than An. arabiensis. Vgsc-1014S was present in An. gambiae (s.l.) populations in Wassadou but not in Kedougou. Ace-1 and rdl mutations were more frequent in An. gambiae (s.s.) in comparison to An. arabiensis and An. coluzzii.

Conclusions: Resistance to all the four insecticide classes tested was detected in southeastern Senegal as well as all target site mutations investigated were found. Data will be used by the national Malaria Control Programme.

Keywords: Insecticide resistance, An. arabiensis, An. coluzzii, An. gambiae (s.s.), Vgsc-1014F, Vgsc-1014S, Ace-1, A296S, A296G, Senegal

*Correspondence: dioufelhadjied@gmail.com

1 Laboratoire d'Écologie Vectorielle et Parasitaire, Université Cheikh Anta Diop de Dakar, Dakar, Senegal

Full list of author information is available at the end of the article

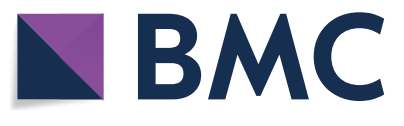

(c) The Author(s) 2020. This article is licensed under a Creative Commons Attribution 4.0 International License, which permits use, sharing, adaptation, distribution and reproduction in any medium or format, as long as you give appropriate credit to the original author(s) and the source, provide a link to the Creative Commons licence, and indicate if changes were made. The images or other third party material in this article are included in the article's Creative Commons licence, unless indicated otherwise in a credit line to the material. If material is not included in the article's Creative Commons licence and your intended use is not permitted by statutory regulation or exceeds the permitted use, you will need to obtain permission directly from the copyright holder. To view a copy of this licence, visit http://creativeco mmons.org/licenses/by/4.0/. The Creative Commons Public Domain Dedication waiver (http://creativecommons.org/publicdomain/ zero/1.0/) applies to the data made available in this article, unless otherwise stated in a credit line to the data. 


\section{Background}

Malaria remains a major public health challenge in endemic countries. It mainly affects vulnerable groups, including pregnant women and children less than five years-old. In most endemic countries, the fight against this endemic disease is based on (i) the early detection of Plasmodium infection by a biological diagnosis of cases (rapid diagnosis test and blood smear), (ii) treatment with effective drugs (artemisinin-based combination therapy $(\mathrm{ACT})$ ), and (iii) prevention (intermittent preventive treatment in pregnancy, seasonal malaria chemoprevention in children under ten years-old and vector control). Worldwide, the number of malaria cases has decreased from 251 million in 2010 to 228 million in 2018 At the same time, the disease incidence declined from 71 to 57 cases per 1000 in 2010 and 2018, respectively [1].

Despite these advances, malaria incidence in Africa has increased between 2014 and 2016 [2], because of factors including the development and spread of insecticide resistance in the main malaria vectors, such as An. funestus and An. gambiae (s.l.). Currently, resistance to at least one of the four major classes of insecticides has been reported in malaria vectors in all African endemic areas [1]. This could be a major obstacle to the efficacy of insecticide-based vector control strategies [3, 4]. Resistance to pyrethroids (the only insecticide class currently approved for long-lasting insecticidal mosquito nets: LLINs) [3, 5, 6] and to DDT (dichlorodiphenyltrichloroethane) [7] has been reported in many endemic settings $[8,9]$, particularly in Asia and in tropical African countries.

Several insecticide resistance mechanisms have been described in the major malaria vectors. The "knock down" resistance $(k d r)$ mutation, which confers resistance to pyrethroids and DDT, is the most common. It occurs at 1014 position of the gene encoding the S6 Trans membrane domain II of para voltage-gated sodium channel (Vgsc), the interaction site of insecticides and protein targets.

Two types of $k d r$ mutation, widely distributed in species of the An. gambiae complex, are reported in many studies in Africa [10-12]. Both mutations are due to substitution: the first mutation changes a leucine to a phenylalanine at amino acid position 1014 of voltage gated sodium channel gene (Vgsc-1014F), whereas the second mutation changes a leucine to a serine at amino acid position 1014 of the same gene: (Vgsc-1014S) [13, 14].

Other target-site mutations have been described in $A n$. gambiae (s.l.). These include the gene encoding acetyl cholinesterase (ace-1) and the gamma-amino butyric acid (GABA) receptor [15]. The ace- $1^{R}$ (acetyl cholinesterase insensible) mutation, caused by a substitution of a glycine to a serine at position 119 (G119S), results in insensitivity of acetyl cholinesterase (AChE1) to organophosphates and carbamates [16]. The GABA receptor mutation results from a nucleotide substitution at amino acid position 296, leading the change of an alanine to a serine in $A n$. arabiensis or a glycine in An. gambiae (s.s.) and $A n$. coluzzii. It generally confers resistance to dieldrin ( $r d l$ A296S or rdl-A296G) or can lead to a cross-resistance to cyclodiene organochlorines and phenyl pyrazole (fipronil) [17].

Previous studies of susceptibility of An. gambiae (s.l.) to insecticides have revealed, often at different levels, a phenotypic resistance to DDT and to pyrethroids in most parts of Senegal, except in the north and extreme southeast $[18-20]$. The aims of this study were to update the current status of insecticide resistance among An. gambiae (s.l.) populations in southeastern Senegal and to identify the mechanisms of insecticide resistance, particularly for target-site mutations involved in insecticide resistance.

\section{Methods \\ Study area}

The study was conducted in October and November 2014 in two sites of southeastern Senegal: Kedougou $\left(12^{\circ} 33^{\prime} 11.3^{\prime \prime} \mathrm{N}, 12^{\circ} 10^{\prime} 09.5^{\prime \prime} \mathrm{W}\right)$ in Kedougou district and Wassadou-Badi $\left(13^{\circ} 22^{\prime} 22.3^{\prime \prime} \mathrm{N}, 13^{\circ} 22^{\prime} 53.5^{\prime \prime} \mathrm{W}\right)$ in Tambacounda district (Fig. 1). The area is bordered by the Republics of Mali and Guinea. The climate is a SudanoGuinean type with a rainy season generally extending from May to October [21]. The average precipitation is between 1200-1300 $\mathrm{mm}$ per year with average temperatures between $33-42{ }^{\circ} \mathrm{C}$ for maxima and $21-25{ }^{\circ} \mathrm{C}$ for minima. Agriculture is the main economic activity with a wide production of sorghum, maize, fonio, rice and cotton. The area of Kedougou is also a gold-mining zone, and has a significant potential for mineral resources. With a malaria incidence greater than 25 per 1000 [22], the study area remains the most holo endemic area in Senegal. In 2014, 265,624 clinical cases were recorded, including 12,636 severe cases [23]. Malaria transmission is seasonal and occurs during the rainy season and the beginning of the dry season. Anopheles gambiae (s.s.), An. coluzzii and An. arabiensis are responsible for most malaria transmission, but in some specific settings, $A n$. funestus and An. nili are involved [24, 25].

\section{Collection of immature stages of Anopheles spp. and mosquito rearing}

Larval collections were carried out in Kedougou, Wassadou and Badi. Wassadou and Badi belong to the same area and are just $1.5 \mathrm{~km}$ apart. The larval sites for $A n$. gambiae (s.l.) consisted of temporary water collections, footprints and hollows associated with human activities. During the study period, immature stages were collected 
from positive larval sites located in or around villages. All larval collections from Kedougou were pooled to form a sample and those of Wassadou and Badi a sample. After collection, immature stages were transferred to a local insectary for rearing. Anopheles larvae were fed with fishmeal (Tetramin Baby ${ }^{\circledR}$; tetraGmbH, Herrenteich 78, Germany). Pupae were collected daily and introduced into rearing cages. At emergence, mosquito adults were fed using absorbent cotton soaked with $10 \%$ sucrose solution.

\section{WHO bioassay tests and morphological identification}

WHO susceptibility tests were performed according to the standardized protocol [26] with adults 3 to 5 days post-emergence from field collected larvae. Eleven insecticides belonging to four insecticide classes were tested: five pyrethroids $(0.05 \%$ deltamethrin, $0.75 \%$ permethrin, $0.05 \%$ lambda-cyhalothrin, $0.1 \%$ alpha-cypermethrin and $0.15 \%$ cyfluthrin), two organochlorines (4\% DDT and $4 \%$ dieldrin), three organophosphates (1\% fenitrothion, $5 \%$ malathion and $1 \%$ pirimiphos-methyl) and one carbamate $(0.1 \%$ bendiocarb). For the pyrethroids and DDT, the number of knockdown individuals was recorded at 10 , $15,20,30,40,50$ and $60 \mathrm{~min}$ during the exposure period. Mortality rates were determined $24 \mathrm{~h}$ post-exposure. The mortality rates in the tested groups were corrected when needed, using Abbot's formula [27] to validate tests results according to mortality rate in controls.

Finally, tested specimens were identified morphologically under a binocular microscope using a conventional key [28] and then individually stored in Eppendorf tubes containing silica-gel. Surviving specimens and 110 randomly selected dead specimens ( 10 for bendiocarb, 20 for organochlorines, 30 for organophosphates and 50 for pyrethroids) were individually stored for laboratory analysis.

\section{DNA extraction, molecular identification of species and detection of $k d r$, ace-1 and $r d l$}

Genomic DNA extraction was carried out by the $2 \%$ CTAB (cetyl trimethyl ammonium bromide) method [29] adapted to animal tissues. Each sample was grounded in an Eppendorf tube containing $200 \mu \mathrm{l}$ of CTAB and incubated at $65{ }^{\circ} \mathrm{C}$ for $1 \mathrm{~h}$. Then $200 \mu \mathrm{l}$ of chloroform was added and mixed by inversion. The mixture was centrifuged at 12,000 $\times$ rpm for $5 \mathrm{~min}$, after which the supernatant containing DNA was recovered in a new Eppendorf tube. DNA was then precipitated with isopropanol and the mixture was then centrifuged at $12,000 \times \mathrm{rpm}$ for $15 \mathrm{~min}$ and washed with $70 \%$ ethanol after a centrifugation of $12,000 \times \mathrm{rpm}$ for $5 \mathrm{~min}$ and then brought to speed-vac for drying. DNA was suspended in molecular biology grade water: DNA/RNA free (Cat \# 10977 035; Invitrogen, Grand Island, NY, USA). One tenth of dilution was carried out before PCR (identification of species of the An. gambiae complex and detection of target site mutations). Species were identified using IMPPCR (intentional mismatch primer-PCR) as described by Wilkins et al. [30]. Kdr mutations (Vgsc-1014F and Vgsc1014S), G119S (ace-1 $\left.{ }^{R}\right)$ and $r d l-296 \mathrm{~S}$ (An. arabiensis) and rdl-296G (An. gambiae (s.s.) and An. coluzzii) were determined using the protocols described by Huynh et al. [31] and by Weill et al. [32] and Du et al. [17] respectively.

\section{Data entry and statistical analysis}

Data were recorded in a Microsoft Excel 2010 spreadsheet. Homogeneity tests of percentages and averages were performed using standard chi-square tests with a $5 \%$ significance level threshold. The level of insecticide susceptibility of mosquitoes was evaluated following the WHO criteria [26] and validated by considering mortality rates of control mosquitoes. If the control mortality was less than $5 \%$, no correction of test results was necessary whereas mortality of $\geq 5 \%$ required Abbott's correction [26]. $\mathrm{KDT}_{50}$ and $\mathrm{KDT}_{95}$ times with $95 \%$ confidence intervals were determined using a log-probit regression model. The mortality rates, the genotypes and allelic frequencies were estimated for each studied population. All statistical analyses and graphs were made using $\mathrm{R}$ software version 3.0.3 [33].

\section{Results}

\section{Susceptibility tests}

A total of 3742 specimens of the An. gambiae complex (between 109 to 240 per insecticide per site) were exposed to the WHO recommended diagnostic doses (2439 from Kedougou and 1303 from Wassadou-Badi). In both sites, a high number of mosquitoes were resistant to all five tested pyrethroids (mortality range $42.8-86.4 \%$ ) as well as to the organochlorines (mortality range from $67.8-83 \%$ for dieldrin and $12.8-55.8 \%$ for DDT in Kedougou and Wassadou-Badi, respectively) (Fig. 2, Table 1). In the group of organophosphates, the populations of $A n$. gambiae (s.l.) tested in both areas were susceptible to $5 \%$ malathion and $1 \%$ pirimiphos-methyl. Fenitrothion resistance (89\% mortality rate, 95\% CI: $85-95 \%)$ was detected in Kedougou, where An. gambiae (s.l.) populations were also resistant to bendiocarb $0.1 \%$ (Fig. 2).

\section{Knockdown times/knockdown effect}

In Kedougou, $\mathrm{KDT}_{50}$ greater than 60 min were recorded for DDT, permethrin and deltamethrin. In WassadouBadi a $\mathrm{KDT}_{50}$ greater than $60 \mathrm{~min}$ were noted with DDT and lambda-cyhalothrin. The $\mathrm{KDT}_{50}$ value for permethrin was 3.5 times higher in Kedougou compared to Wassadou-Badi $\left(\chi^{2}=10.029, d f=1, P=0.0015\right)$. However, $\mathrm{KDT}_{50}$ value for deltamethrin in Kedougou was 2.7 higher 
than $\mathrm{KDT}_{50}$ value of Wassadou-Badi $\left(\chi^{2}=3.0083, d f=1\right.$, $P=0.0828$ ) and no significant difference was observed between these two sites. Conversely, for cyfluthrin and lambda-cyhalothrin, $\mathrm{KDT}_{50}$ were respectively 1.8 and 1.18 times higher in Wassadou-Badi $\left(\chi^{2}=19.3177, d f=1\right.$, $\left.P<0.0001 ; \chi^{2}=15.2239, d f=1, P<0.0001\right)$. Cyfluthrin and alpha-cypermethrin had the lowest KDT50 compared to other pyrethroids tested (Table 1).

Vgsc-1014F, Vgsc-1014S, ace-1 (G119S), rdl-A296S and $r d l-A 296 G$ mutation frequencies in An. arabiensis, An. coluzzii and An. gambiae (s.s.)

The frequency of $k d r(V g s c)$ gene mutations was different among the three different members of the An. gambiae complex. The wild-type allele dominated in both Kedougou and Wassadou-Badi in An. arabiensis. In An. gambiae (s.s.) and $A n$. coluzzii population, a predominance of FF homozygotes was noted in both sites for the Vgsc1014F mutation. The results revealed two homozygous hybrids resistant to the Vgsc-1014F mutation. The Vgsc$1014 S$ mutation was not found any member of the $A n$. gambaie complex in Kedougou but was predominant in the An. arabienesis in Wassadou-Badi.

The allelic frequencies of the Vgsc-1014F mutation (Kedougou: Fisher's exact test: OR: 221.48, 95\% CI: 29.39494.2, $P<0.001$; Wassadou-Badi: $\chi^{2}=455.3289, d f=2$, $P<0.001$ ) and $V g s c-1014 S$ (Wassadou-Badi: Fisher's exact test: OR: $0.00,95 \%$ CI: $0.00-0.96, P<0.001)$ were significantly higher in An. gambiae (s.s.) compared to An. coluzzii and An. arabiensis (Table 2).

The wild-type allele was the most frequent allele for the ace- $1^{R}$ for all species of the An. gambiae complex in both sites. The frequency of the ace- $1^{R}$ (G119S) mutation was low in both sites and heterozygotes genotypes (GS) were predominant for carriers of an 119S allele.

In Wassadou-Badi, a relatively higher allelic frequency was noted in An. gambiae (s.s.), the only species in which all SS homozygotes were found (Table 2). As with ace$1^{R}$, the predominant allele for $r d l$ gene was the wild type allele. The mean allelic frequencies of A296S or A296G were significantly different among species of the $A n$. gambiae complex in Kedougou (Fisher's exact test: OR: 7.95, 95\% CI: $1.30-326.6, P=0.0147$ ), but not in Wassadou-Badi (Fisher's exact test: OR: inf, $P=0.12$ ). However, only An. gambiae (s.s.) population has homozygous (GG) for A296G $r d l$ allele (Table 2).

\section{Allelic frequencies at the Vgsc-1014F, Vgsc-1014S, ace-1 ${ }^{R}$ (G119S) and $r d l-A 2965$ or $r d l-A 296$ G locus according to the phenotype after insecticide exposure}

Table 3 shows the allelic frequencies of the Vgsc-1014F, $V g s c-1014 S, \quad$ G119S and $r d l-A 296 G$ or $r d l-A 296 S$ mutations in the selected specimens that survived or died after exposure to insecticides.

In both study areas, An. gambiae (s.s.) was the predominant species among surviving specimens $(96.6 \%$ in Kedougou; $64.1 \%$ in Wassadou-Badi). The percentage of An. gambiae (s.s.) was higher in surviving compared to the dead specimens $\left(\chi^{2}=32.4, d f=1, P<0.0001\right)$ while An. arabiensis $(82.7 \%, n=52)$ predominated only in dead specimens in Wassadou-Badi.

In An. gambiae (s.s.), the frequencies of resistant allele in surviving versus dead specimens after exposition to DDT and pyrethroids were comparable for the 1014F allele (Fisher's exact test: OR: 0.00; 95\% CI: 0.0-2.4, $P \geq 0.057$ ) and significantly different between those specimens exposed to bendiocarb and fenitrothion for the ace- $^{R}$ (G119S) allele (Fisher's exact test: OR: 0.15 ; $95 \%$ CI: $0.040-0.45, P \leq 0.001)$ in both sites (Table 3).

In Wassadou-Badi, the frequencies of the $1014 \mathrm{~S}$ allele in An. arabiensis (0.34 vs 0.06, Fisher's exact test: OR: 0.09; 95\% CI: $0.02-0.28, P<0.001)$ as well as that of the rdl-296G allele in An. gambiae (s.s.) (0.21 vs 0.0, Fisher's exact test: OR: 0.00 ; $95 \%$ CI: $0.00-0.60, P=0.004$ ) were higher in surviving compared to the dead specimens after exposure to dieldrin in Kedougou. On the other hand, there was no significant difference between the frequencies of the $1014 \mathrm{~F}$ allele in dead and surviving specimens in both An. gambiae (s.s.) (0.98 vs 0.88, Fisher's exact test, OR: 0.17 ; 95\% CI: $0.02-1.96, P=0.07$ ) and An. arabiensis (0.068 vs 0.0, Fisher's exact test: OR: 0.00; 95\% CI: $0.0-0.0 .83, P=0.017$ ).

\section{Discussion}

This study aimed to update data relating to insecticide susceptibility and to determine the frequencies of mutations of $k d r$ ( $V g s c-1014 \mathrm{~F}$ and $V g s c-1014 S)$, ace$1^{R}$ and $r d l$ alleles associated with the resistance of $A n$. gambiae (s.l.) populations to insecticides in southeastern Senegal.

The results of the WHO susceptibility tests showed vector resistance to pyrethroids organochlorines (DDT and dieldrin) and carbamates insecticides that are recommended by PQT-VC (Prequalification Team: Vector Control Products). These insecticides are the only ones currently approved for LLIN treatment [34, 35], and are offered by nongovernmental organizations such as the United States President's Malaria Initiative (PMI) and Senegal River Basin Development Organization (OMVS). The use of LLINs over several years could have led to the increase of resistance genes in vectors of An. gambiae species complex, through selection pressure $[36,37]$. The resistance of An. gambiae (s.l.) to pyrethroids has been 


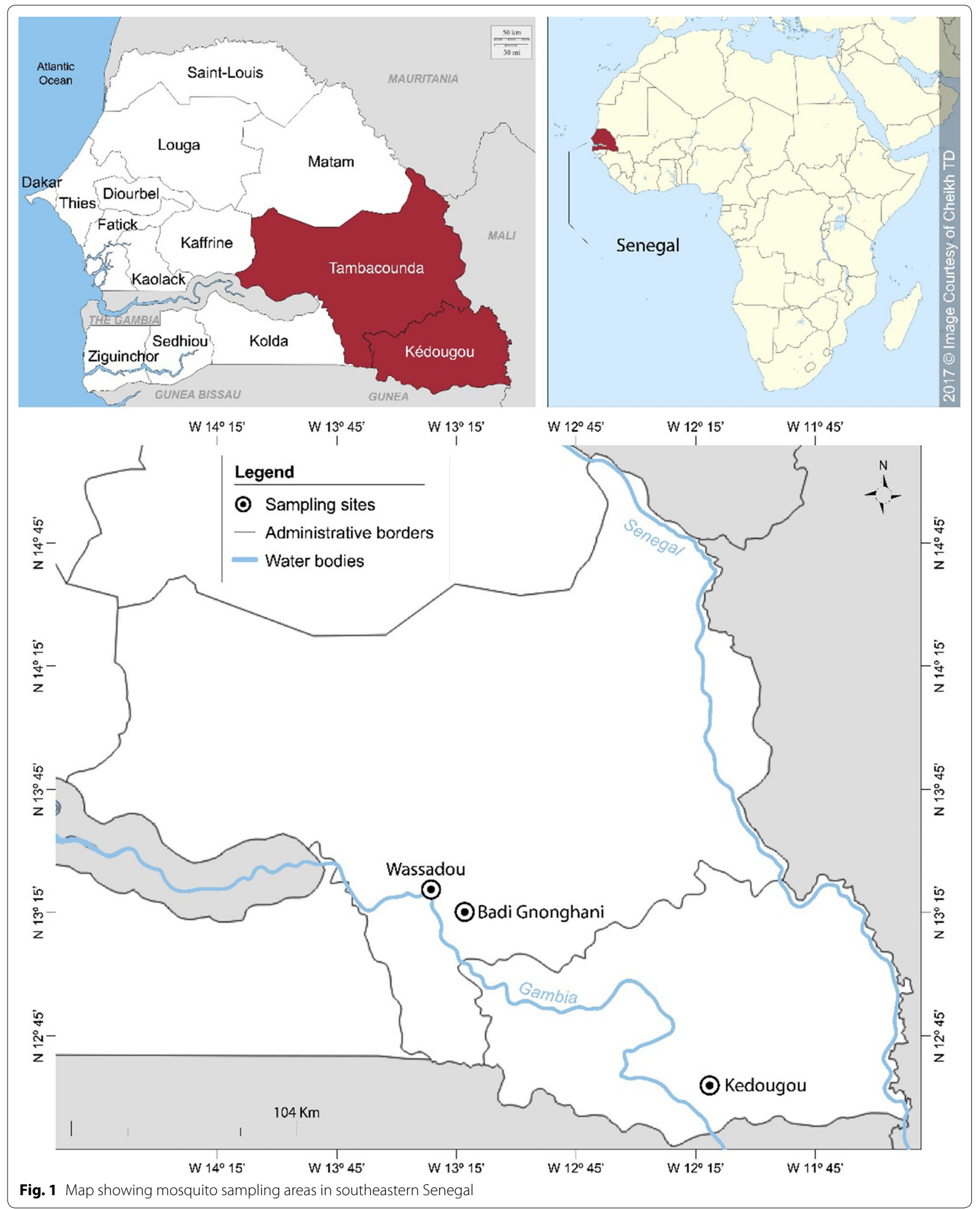




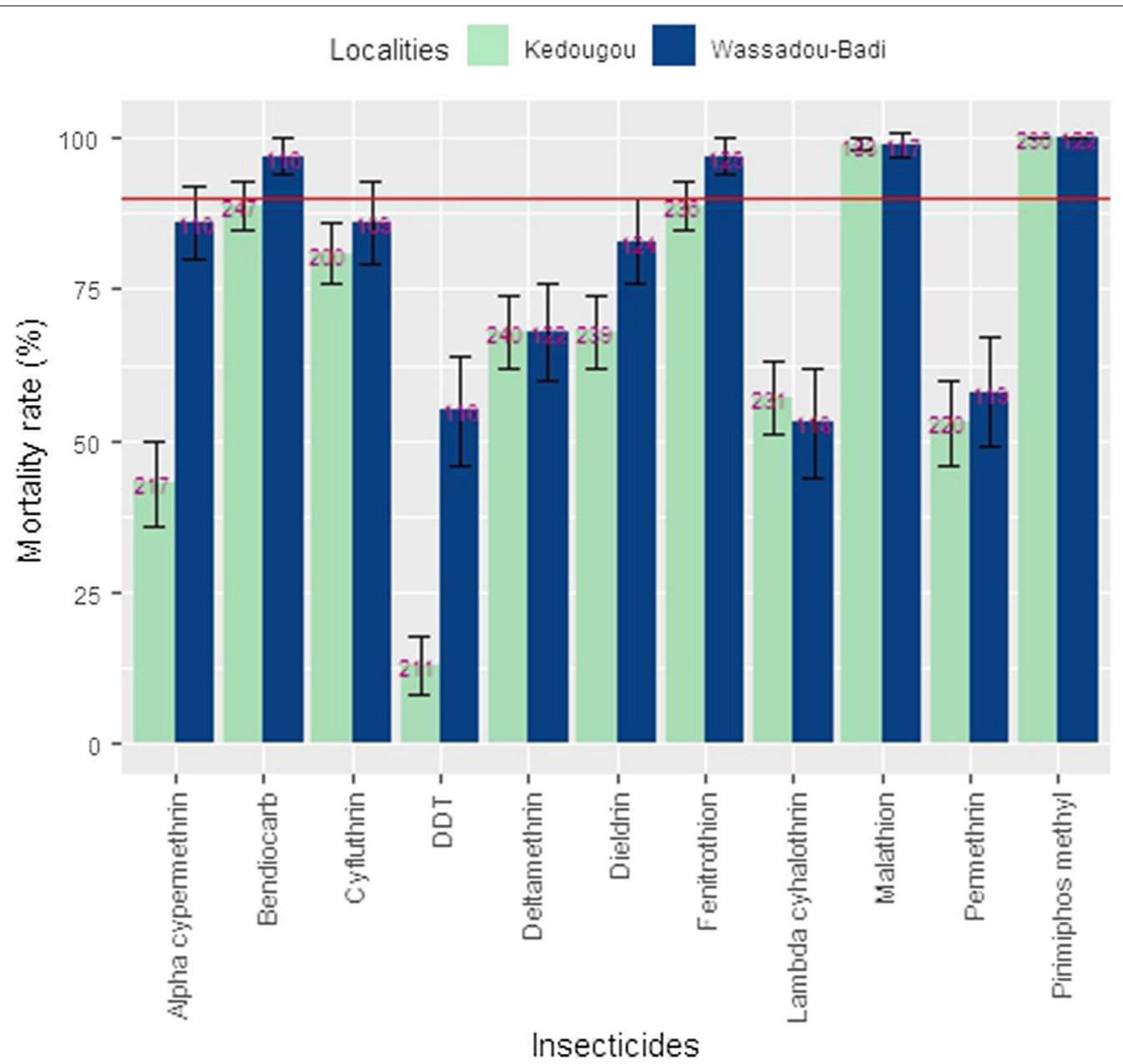

Fig. 2 Mortality rates of Anopheles gambiae (s.l.) $24 \mathrm{~h}$ populations after exposure to WHO recommended insecticide doses in October and November 2014

shown to be strongly associated with their excessive use in agriculture especially in cotton growing areas [38].

Moreover, An. gambiae (s.l.) populations in the area were also resistant to organochlorines (DDT and dieldrin). Since the first malaria eradication attempt, DDT and dieldrin resistance phenotypes have been reported in many African countries by Hamon \& Garrett-Jones [39]. Despite several decades of non-use, DDT may persist in the environment due to lack of microbial degradation system [40].

Previous studies have reported resistance only to DDT and pyrethroids in southeastern and central Senegal where LLIN use is high $[19,20]$. However, unlike previous studies conducted in Senegal, this study shows that vectors are resistant to almost all tested pyrethroids and bendiocarb.

Bioassays likewise showed resistance to bendiocarb in Kedougou. This resistance could result from selection pressure in larval from insecticide residues (bendiocarb) used on cotton crops by SODEFITEX [41]. This phenotypic resistance to bendiocarb should be closely monitored as there is cross-resistance to carbamates and organophosphates.

The search for mutations involved in the phenotypic resistance of An. gambiae (s.l.) population to insecticides showed the presence of Vgsc-1014F, Vgsc-1014S, ace1 (G119S) and $r d l$-A296S or $r d l$-A296G mutations. The Vgsc-1014S mutation was not found in An. gambiae (s.l.) from Kedougou, where the $V g s c-1014 \mathrm{~F}$ was at $0.99 \mathrm{in} \mathrm{An}$. gambiae (s.s). Although not yet fixed in Wassadou-Badi, the allelic frequency of $V g s c-1014 \mathrm{~F}$ mutation was greater than 0.50 .

The frequency of the $V g s c-1014 \mathrm{~F}$ mutation was higher both in the surviving and dead phenotypes in the An. gambiae (s.s.) populations from Kedougou. The frequency of the Vgsc-1014S mutation in An. arabiensis populations from Wassadou-Badi was higher in the surviving than the dead specimens whereas no 
Table 1 Mortality rates following insecticides (pyrethroids, DDT and dieldrin) exposure of Anopheles gambiae (s.l.) populations from Kedougou and Wassadou-Badi in October and November 2014

\begin{tabular}{lllll}
\hline Locality & Insecticide & Mortality rate (\%) (n) & $\begin{array}{l}\mathrm{KDT}_{50} \text { (min) } \\
(95 \% \mathrm{Cl})\end{array}$ & $\begin{array}{l}\mathrm{KDT}_{95}(\mathrm{~min}) \\
(95 \% \mathrm{Cl})\end{array}$ \\
\hline Kedougou & & $161(119.3-267.1)$ & $784.95(420.5-2287.9)$ \\
& DDT & $12.8(211)$ & $164.89(122.6-263.2)$ & $1234.25(634-3563.8)$ \\
& Permethrin & $53.2(220)$ & $161(128-222.8)$ & $784.95(490.7-1556.5)$ \\
& Deltamethrin & $67.9(240)$ & $53.92(49.2-60.5)$ & $149.27(118.7-208.3)$ \\
& Lambda-cyhalothrin & $57.1(231)$ & $22.72(20.7-24.8)$ & $65.63(56.4-80.2)$ \\
& Cyfluthrin & $81.4(200)$ & $28.35(26.8-30)$ & $84(74.9-96.6)$ \\
Wassadou-Badi & Alpha-cypermethrin & $42.8(217)$ & $97.56(73.3-324.7)$ & $223.3(123.2-3120.3)$ \\
& dieldrin & $67.8(239)$ & $161(119.3-267.1)$ & $784.95(420-2287.9)$ \\
& DDT & $55.8(116)$ & $47.47(43.4-52.9)$ & $153.23(121.9-210)$ \\
& Permethrin & $58(119)$ & $58.8(50.0-68.0)$ & $113.38(97.73-139.3)$ \\
& Deltamethrin & $68(122)$ & $63.56(56.5-75.5)$ & $174.65(130.3-280.7)$ \\
& Lambda-cyhalothrin & $53.4(118)$ & $41.7(49.8-105.6)$ & $87.45(87.5-139.6)$ \\
& Cyfluthrin & $86.4(109)$ & $27.63(25.6-29.7)$ & $62.94(55.8-73.6)$ \\
& Alpha-cypermethrin & $86(110)$ & $0(-)$ & $0(-)$
\end{tabular}

Abbreviations: $\mathrm{n}$, number of mosquitoes tested; $95 \% \mathrm{Cl}, 95 \%$ confidence interval; $\mathrm{KDT}_{50}$ and $\mathrm{KDT}_{95}$, $\mathrm{knock}_{\text {down }} 50 \%$ and $95 \%$; min, minutes

Table 2 Genotypes and allelic frequencies of mutations Vgsc-1014F, Vgsc-1014S, Ace-1 (G119S), rdl-A296S, and rdl-A296G in An. arabiensis, An. coluzzii and An. gambiae (s.s.) in Kedougou and Wassadou-Badi in October and November 2014

\begin{tabular}{|c|c|c|c|c|c|c|c|c|c|c|c|}
\hline \multirow[t]{2}{*}{ Localities } & \multirow[t]{2}{*}{ Species } & \multicolumn{4}{|c|}{ Vgsc-1014F } & \multirow[t]{2}{*}{$P$} & \multicolumn{4}{|c|}{ Vgsc-1014S } & \multirow[t]{2}{*}{ P } \\
\hline & & LL & LF & $\mathrm{FF}$ & (freq R) & & LL & LS & SS & (freq R) & \\
\hline \multirow[t]{3}{*}{ Kedougou } & An. arabiensis & 23 & 1 & 3 & 0.129 & $<0.001$ & 14 & 0 & 0 & 0.00 & na \\
\hline & An. coluzzii & 0 & 1 & 18 & 0.973 & & 0 & 0 & 0 & 0.00 & \\
\hline & An. gambiae (s.s.) & 0 & 1 & 298 & 0.998 & & 2 & 0 & 0 & 0.00 & \\
\hline \multirow[t]{3}{*}{ Wassadou-Badi } & An. arabiensis & 114 & 3 & 3 & 0.037 & $<0.001$ & 55 & 11 & 12 & 0.22 & $<0.001$ \\
\hline & An. coluzzii & 10 & 5 & 10 & 0.500 & & 8 & 0 & 0 & 0.00 & \\
\hline & An. gambiae (s.s.) & 3 & 0 & 134 & 0.978 & & 0 & 0 & 10 & 1 & \\
\hline \multirow[t]{2}{*}{ Localities } & Species & \multicolumn{4}{|c|}{ Ace-1 (G119S) } & $P$ & \multicolumn{4}{|c|}{ Rdl-A296S or Rdl-A296G } & $P$ \\
\hline & & GG & GS & SS & (freq R) & & $\mathrm{AA}$ & $A G$ & GG & (freq R) & \\
\hline \multirow[t]{3}{*}{ Kedougou } & An. arabiensis & 1 & 0 & 0 & 0.00 & 0.33 & 25 & 1 & 0 & 0.019 & 0.014 \\
\hline & An. coluzzii & 19 & 1 & 0 & 0.025 & & 11 & 1 & 0 & 0.041 & \\
\hline & An. gambiae (s.s.) & 101 & 28 & 7 & 0.154 & & 145 & 49 & 2 & 0.135 & \\
\hline \multirow[t]{3}{*}{ Wassadou-Badi } & An. arabiensis & 38 & 3 & 0 & 0.036 & 0.043 & 32 & 0 & 0 & 0.00 & 0.124 \\
\hline & An. coluzzii & 21 & 0 & 0 & 0.00 & & 4 & 0 & 0 & 0.00 & \\
\hline & An. gambiae (s.s.) & 57 & 11 & 6 & 0.155 & & 44 & 4 & 1 & 0.061 & \\
\hline
\end{tabular}

Abbreviations: $P$, probability of significant difference for each mutation among species within each site; $L$, leucine; $F$, phenylalanine; $S$, serine; $G$, glycine; $A$, alanine; Freq $\mathrm{R}$, frequency of resistant allele; na, not applicable, $F F$, phenyl alanine- phenyl alanine

correlations were detected between the Vgsc-1014F mutation and the resistance phenotype in An. gambiae (s.s.) and An. coluzzii. It is therefore likely that mechanisms other than $V g s c-1014 \mathrm{~F}$ mutation are involved in the insecticide resistance of these species. This hypothesis should be investigated in the future. These results are in line with those of Thiaw et al. [20] and Ahoua et al. [42], who found no correlation between the $k d r$ mutation and the phenotypic alive or dead phenotypic, respectively, in An. arabiensis and An. coluzzii. Only the Vgsc-1014F mutation was noted in An. coluzzii. This finding could be explained by introgression from $A n$. gambiae (s.s.) to An. coluzzii [43, 44]. Furthermore, our results show an absence of the $V g s c-1014 S$ mutation in 
Table 3 Numbers of specimens and frequencies of G119S and rdl A296G or rdl A296S mutations by surviving or dead phenotypes in An. arabiensis, An.coluzzii and An. gambiae (s.s.) of Kedougou and Wassadou-Badi in October and November 2014

\begin{tabular}{|c|c|c|c|c|c|c|c|c|c|c|}
\hline Locality & Phenotype & $n$ & $\begin{array}{l}\text { An. arabiensis } \\
\text { (freq } \mathrm{R} \text { ) }\end{array}$ & P & $n$ & $\begin{array}{l}\text { An. coluzzii } \\
\text { (freq R) }\end{array}$ & $P$ & $n$ & $\begin{array}{l}\text { An. } \\
\text { gambiae } \\
\text { (s.s.) } \\
\text { (freq R) }\end{array}$ & P \\
\hline \multicolumn{11}{|l|}{ Kedougou } \\
\hline \multirow[t]{2}{*}{ Vgsc-1014F } & Surviving & 11 & 0.31 & 0.031 & 18 & 0.97 & & 248 & 1.0 & \\
\hline & Dead & 16 & 0.06 & & 0 & 0.0 & na & 15 & 0.97 & 0.057 \\
\hline \multirow[t]{2}{*}{ Vgsc-1014S } & Surviving & 2 & 0.00 & na & 1 & 0.00 & & 42 & 0.00 & \\
\hline & Dead & 12 & 0.00 & & 0 & 0.00 & & 16 & 0.00 & na \\
\hline \multicolumn{11}{|l|}{ Wassadou-Badi } \\
\hline \multirow[t]{2}{*}{ Vgsc-1014F } & Surviving & 51 & 0.068 & 0.017 & 11 & 0.6 & 0.44 & 100 & 0.98 & \\
\hline & Dead & 41 & 0 & & 8 & 0.37 & & 9 & 0.88 & 0.07 \\
\hline \multirow[t]{2}{*}{ Vgsc-1014S } & Surviving & 24 & 0.48 & & 3 & 0.00 & & 51 & 1.0 & \\
\hline & Dead & 33 & 0.07 & $<0.001$ & 7 & 0.00 & na & 6 & 0.00 & na \\
\hline \multicolumn{11}{|l|}{ Kedougou } \\
\hline \multirow[t]{2}{*}{ Ace-1 G119S } & Surviving & 21 & 0.00 & na & 0 & 0.00 & & 31 & 0.47 & \\
\hline & Dead & 33 & 0.00 & & 2 & 0.00 & na & 22 & 0.11 & $<0.001$ \\
\hline \multirow[t]{2}{*}{ Rdl-A296S or Rdl-A296G } & Surviving & 2 & 0.00 & na & 2 & 0.00 & & 34 & 0.21 & \\
\hline & Dead & 0 & 0.00 & & 0 & 0.00 & na & 15 & 0.00 & 0.004 \\
\hline \multicolumn{11}{|l|}{ Wassadou-Badi } \\
\hline \multirow[t]{2}{*}{ Ace-1 G119S } & Surviving & 0 & 0.00 & na & 1 & 0.00 & na & 11 & 0.36 & 0.034 \\
\hline & Dead & 11 & 0.00 & & 1 & 0.00 & & 6 & 0.00 & \\
\hline \multirow[t]{2}{*}{ Rdl-296S or Rdl-A296G } & Surviving & 2 & 0.00 & na & - & - & - & - & - & - \\
\hline & Dead & 6 & 0.00 & & - & - & - & - & - & - \\
\hline
\end{tabular}

Abbreviations: freq $\mathrm{R}$, allelic frequency of mutation studied; $n$, number of treated specimens; na, not applicable

An. coluzzii. This finding is similar to results obtained in Benin [45], but not those obtained in Cameroon [46] and in the Republic of Equatorial Guinea [47]. The occurrence of the Vgsc-1014F mutation was detected in two hybrids (An. gambiae (s.s.)/An. coluzzii) and were homozygote-resistant genotype (FF). To our knowledge, this is the first report of this mutation in hybrids of An. gambiae (s.s.) and An. coluzzii in Senegal. Other mutations could be involved in resistance of An. gambiae (s.l.) to insecticides, including the Vgsc-1575Y mutation [48] that was not investigated in this study.

With a significantly higher frequency in surviving specimens after exposure, the study shows that the ace$1^{R}$ mutation was implicated in phenotypic resistance of An. gambiae (s.s.) to bendiocarb. The involvement of the ace- $1^{R}$ mutation in the phenotypic resistance to bendiocarb has been reported in An. gambiae (s.s.) populations from Côte Ivoire [42] and Ghana [49]. However, it was not present in surviving An. arabienesis.

The presence of heterozygotes in surviving specimens may explain the resistance of An. gambiae (s.l.) population to carbamates (bendiocarb) from Kedougou and Wassadou-Badi and organophosphates (fenitrothion) from Kedougou area.
Often associated with $r d l$ mutation ( $r d l$-A246S or $r d l$-A296G), the phenotypic resistance to dieldrin was found in An. gambiae (s.l.) populations in both localities. A similar result was obtained in Benin [50]. The allelic frequencies obtained in our study are quite similar to those described by Corbel et al. [50]. The phenotypic resistance to dieldrin could be explained by the long use of dieldrin in the past or other insecticides belonging to different families (such as fipronil or lindane) with the same mode of action as dieldrin on one hand and by the presence of $r d l$ - A296G mutation, which is associated with a $2 \mathrm{La}$ chromosomal polymorphic on the other hand [50,51]. This is a very stable polymorphic inversion that limits crossover and would help preserve this mutation in a given population. The occurrence of multiple-resistance locus in An. gambiae (s.s), the main malaria vector in the study area, is indicative of the genes involved in resistance to the insecticides used in this area.

\section{Conclusions}

The study demonstrates phenotypic resistance in $A n$. gambiae (s.l.) population to DDT, pyrethroids, benbiocarb and fenitrothion in southeastern Senegal. The 
relatively higher frequency in specimens surviving insecticide exposure demonstrates the role of target site modifications, including Vgsc-1014F and Vgsc-1014S, ace- $1^{R}$ and $r d l$-A296S or $r d l$-A296G. Though they are one of the main factors, investigation of other mechanisms involved remains necessary for better management of the resistance in An. gambiae (s.l.) populations. Resistance to insecticides may jeopardize the effectiveness of the main strategies (indoor residual spraying (IRS) of persistent insecticides and the use LLIN mosquito nets) to reduce malaria transmission in the area.

\begin{abstract}
Abbreviations
CTAB: Cetyl trimethyl ammonium bromide; PCR: Polymerase chain reaction; kdr: Knockdown resistance; $r d l$ : Resistance to dieldrin; OMVS: Senegal River Basin Development Organization; IMP-PCR: Intentional mismatches primerPCR; DDT: Dichloro diphenyltrichloroethane; ace-1: Target-site resistance gene for carbamate and organophosphate insecticides conferring insensitive acetyl cholinesterase; Vgsc: Voltage-gated sodium channel; WHO: World Health Organization; LLINs: Long-lasting insecticide-treated nets; ace $7^{R}$ : Acetyl cholinesterase insensible (G119S); Vgsc-1575Y: Polymorphism non-synonym; PMl: United States President's Malaria Initiative; KDT 50 and KDT $_{95}$ : Knockdown 50\% and 95\%; GABA: Gamma-amino butyric acid; IRS: Indoor residual spraying of insecticides; PQT-VC: Prequalification team-vector control products; s.l.: sensu lato; s.s.: sensu stricto; P: Probability.
\end{abstract}

\section{Acknowledgements}

We sincerely thank the PMI (President's Malaria Initiative) and the National Malaria Control Programme in Senegal. We thank Dr Ellen M. Dotson (Centers for Disease Control and prevention, Atlanta, USA) and Mr Omar Thiaw (Institut de Recherche pour le Développement, UMR Vecteurs-Infections Tropicales et Méditerranéennes, Dakar, Sénégal) for their valuable contribution.

\section{Authors' contributions}

ED and EAN were involved field data collections. ED and AK performed the laboratory analyses. ED, DI and KL performed the data analyses. ED, EAN, MD, $L K, I D, O F$ and BS reviewed and edited the manuscript. All authors read and approved the final manuscript.

\section{Funding}

This study was supported by PMI (President's Malaria Initiative) monitoring activities in Senegal.

\section{Availability of data and materials}

Data supporting the conclusions of this article are included within the article. The data used and analyzed during the current study are available from the corresponding author upon reasonable request.

\section{Ethics approval and consent to participate}

Not applicable.

\section{Consent for publication}

Not applicable.

\section{Competing interests}

The authors declare that they have no competing interests.

\section{Author details}

${ }^{1}$ Laboratoire d'Écologie Vectorielle et Parasitaire, Université Cheikh Anta Diop de Dakar, Dakar, Senegal. ${ }^{2}$ Institut Pasteur de Dakar, Dakar, Senegal.

Received: 25 July 2020 Accepted: 30 October 2020

Published online: 11 November 2020

\section{References}

1. WHO. World malaria report 2019. Geneva: World Health Organization; 2019. https://www.who.int/publications/i/item/world-malaria-repor $\mathrm{t}-2019$.

2. WHO. World malaria report 2017. Geneva: World Health Organization; 2017. https://www.who.int/publications/i/item/world-malaria-repor $\mathrm{t}-2017$.

3. Ranson H, N'Guessan R, Lines J, Moiroux N, Nkuni Z, Corbel V. Pyrethroid resistance in African anopheline mosquitoes: what are the implications for malaria control? Trends Parasitol. 2011;27:91-8.

4. Dabiré RK, Namountougou M, Diabaté A, Soma DD, Bado J, Toé HK, et al. Distribution and frequency of kdr mutations within Anophelesgambiae (s.l.) populations and first report of the ace.1 G119S mutation in Anophelesarabiensis from Burkina Faso (West Africa). PLoS ONE. 2014;9:e101484.

5. Sangba MLO, Deketramete T, Wango SP, Kazanji M, Akogbeto M, Ndiath MO. Insecticide resistance status of the Anophelesfunestus population in Central African Republic: a challenge in the war. Parasit Vectors. 2016;9:230.

6. Camara S, Koffi AA, Alou LP, Koffi K, Kabran JPK, Koné A, et al. Mapping insecticide resistance in Anophelesgambiae (s.l.) from Côte d'Ivoire. Parasit Vectors. 2018;11:19.

7. Fossog Tene B, Poupardin R, Costantini C, Awono-Ambene P, Wondji CS, Ranson H. Resistance to DDT in an urban setting: common mechanisms implicated in both $\mathrm{M}$ and $\mathrm{S}$ forms of Anopheles gambiae in the city of Yaoundé Cameroon. PLoS ONE. 2013;8:e61408

8. Awolola TS, Oduola OA, Strode C, Koekemoer LL. Evidence of multiple pyrethrinoid resistance mechanism in malaria vector Anopheles gambiae (s.s) from Nigeria. Am J Trop Med Hyg. 2008;103:1139-45.

9. Wondji CS, Coleman M, Kleinschmidt I, Mzilahowa T, Irving H, Ndula M, et al. Impact of pyrethroid resistance on operational malaria control in Malawi. Proc Natl Acad Sci USA. 2012;109:19063-70.

10. Foster GM, Coleman M, Thomsen E, Ranson H, Yangalbé-Kalnone E, Moundai T, et al. Spatial and temporal trends in insecticide resistance among malaria vectors in Chad highlight the importance of continual monitoring. PLOS ONE. 2016;11:e0155746.

11. Keita K, Camara D, Barry Y, Osse R, Wang L, Sylla M, et al. Species identification and resistance status of Anophelesgambiae (s.l.) (Diptera: Culicidae) mosquitoes in Guinea. J Med Entomol. 2017;54:677-81.

12. Okorie PN, Ademowo GO, Irving H, Kelly-Hope LA, Wondji CS. Insecticide susceptibility of Anopheles coluzzii and Anopheles gambiae mosquitoes in Ibadan, South-West Nigeria. Med Vet Entomol. 2015;29:44-50.

13. Martinez-Torres D, Chandre F, Williamson MS, Darriet F, Berge JB, Devonshire AL, et al. Molecular characterization of pyrethroid knockdown resistance $(k d r)$ in the major malaria vector Anopheles gambiae s.s. Insect Mol Biol. 1998;7:179-84.

14. Ranson H, Jensen B, Vulule JM, Wang X, Hemingway J, Collins FH. Identification of a point mutation in the voltage-gated sodium channel gene of Kenyan Anopheles gambiae associated with resistance to DDT and pyrethroids. Insect Mol Biol. 2000;9:491-7.

15. Brooke BD, Hunt RH, Coetzee M. Resistance to dieldrin + fipronil assorts with chromosome inversion $2 \mathrm{La}$ in the malaria vector Anopheles gambiae. Med Vet Entomol. 2000;14:190-4.

16. Weill M, Lutfalla G, Mogensen K, Chandre F, Berthomieu A, Berticat C, et al. Comparative genomics: insecticide resistance in mosquito vectors. Nature. 2003:423:136-7.

17. Du W, Awolola TS, Howell P, Koekemoer LL, Brooke BD, Benedict MQ, et al. Independent mutations in the Rdl locus confer dieldrin resistance to Anopheles gambiae and An.arabiensis. Insect Mol Biol. 2005;14:179-83.

18. Faye O, Konate L, Diop A. Profil entomologique du paludisme au Sénégal. Unpublished: Ministère de la Santé et de la Prévention Médicale; 2011.

19. Niang EA, Konaté L, Diallo M, Faye O, Dia I. Patterns of insecticide resistance and knock down resistance $(\mathrm{kdr})$ in malaria vectors An. arabiensis, An. coluzzii and An. gambiae from sympatric areas in Senegal. Parasit Vectors. 2016:9:71.

20. Thiaw O, Doucouré S, Sougoufara S, Bouganali C, Konaté L, Diagne N, et al. Investigating insecticide resistance and knock-down resistance $(k d r)$ mutation in Dielmo, Senegal, an area under long lasting insecticidaltreated nets universal coverage for 10 years. Malar J. 2018;17:123.

21. Food and Agriculture Organization. Animal Production and Health paper 41, Integrating crops and livestock in West Africa. 1983. https://www.fao. org/docrep/004/x6543e/x6543e01.htm. Accessed 25 Mar 2014. 
22. Bulletin épidémiologique annuel du paludisme au SENEGAL; 2016. https ://www.pnlp.sn/2016.

23. Bulletin épidémiologique annuel du paludisme au SENEGAL; 2014. https ://www.pnlp.sn/2014/.

24. Dia I, Diop T, Rakotoarivony I, Kengne P, Fontenille D. Bionomics of Anopheles gambiae Giles, An. arabiensis Patton, An. funestus Giles and An. nili (Theobald) (Diptera: Culicidae) and transmission of Plasmodium falciparum in a Sudano-Guinean zone (Ngari, Senegal). J Med Entomol. 2003:40:279-83.

25. Ndiath MO, Mazenot C, Gaye A, Konate L, Bouganali C, Faye O, et al. Methods to collect Anopheles mosquitoes and evaluate malaria transmission: a comparative study in two villages in Senegal. Malar J. 2011;10:270.

26. WHO. Test procedures for insecticide resistance monitoring in malaria vectors mosquitoes. Geneva: World Health Organization; 2013. https:// www.who.int/malaria/publications/atoz/9789241505154.

27. Abbott WS. A method of computing the effectiveness of an insecticide. J Ecol Entomol. 1925;18:265-7.

28. Gillies MT, De Meillon B. The Anophelinae of Africa South of the Sahara (Ethiopian zoogeographical region). Publ S Afr Inst Med Res. 1968;54:343.

29. Murray MG, Thompson WF. Rapid isolation of high molecular weight plant DNA. Nucleic Acids Res. 1980;8:4321-5.

30. Wilkins EE, Howell PI, Benedict MQ. IMP PCR primers detect single nucleotide polymorphisms for Anopheles gambiae species identification, Mopti and Savanna rDNA types, and resistance to dieldrin in Anopheles arabiensis. Malar J. 2006:5:125.

31. Methods in Anopheles research manual full version (MR4). 2014. p. 250-1. https://www.beiresources.org.

32. Weill H, Hughes JM, Churg AM. Changing trends in US mesothelioma incidence. Occup Environ Med. 2004;61:438-41.

33. R Development Core Team. R: a language and environment for statistical computing. Vienna: R Foundation for Statistical Computing. 2014. https:// www.R-project.org/.

34. Hakizimana E, Karema C, Munyakanage D, Iranzi G, Githure J, Tongren JE, et al. Susceptibility of Anopheles gambiae to insecticides used for malaria vector control in Rwanda. Malar J. 2016;15:582.

35. Dadzie S, Appalu MA, Kerah-Hinzoumbé C, Akogbeto MC, Adimazoya $\mathrm{M}$, Israël DK, et al. Species composition and insecticide resistance status of Anophelesgambiae (s.l.) (Culicidae) in Kome, southern Chad and the implications for malaria control. Parasit Vectors. 2016;9:465.

36. Zoh DD, Ahoua Alou LP, Toure M, Pennetier C, Camara S, Traore DF, et al. The current insecticide resistance status of Anopheles gambiae (s.l.) (Culicidae) in rural and urban areas of Bouaké, Côte d'Ivoire. Parasit Vectors. 2018;11:118.

37. Thwing J, Perry RT, Townes DA, Diouf MB, Ndiaye S, Thior M. Success of Senegal's first nationwide distribution of long-lasting insecticide-treated nets to children under five - contribution toward universal coverage. Malar J. 2011;10:86

38. Diabate A, Baldet T, Fabrice C, Akogbeto M, Guiguemde TR, Darriet F, et al. the role of agricultural use of insecticides in resistance to pyrethroids in Anophelesgambiaes.l. in Burkina Faso. Am J Trop Med Hyg. 2002;67:617-22.

39. Hamon J, Garrett-Jones C. La résistance aux insecticides chez des vecteurs majeurs du paludisme et son importance opérationnelle. Bull OMS 1963;28:1-24

40. Samir SR, Leo MLN. Pesticides: evaluation of environmental pollution. Boca Raton: CRC Press; 2012.
41. Appel d'offre $N^{\circ} 39 / 2014 / D O C / D P C$ portant sur la fourniture de produits insecticides destines à la cotonnière. https://www.sodefitex.sn/image s/2014.pdf.

42. Ahoua AL, Koffi AA, Adja MA, Assi SB, Kouassi PK, N'Guessan R. Status of pyrethroid resistance in Anophelesgambiaes.s. M form prior to the scaling up of long-lasting insecticidal nets (LLINs) in Adzopé, eastern Côte d'Ivoire. Parasit Vectors. 2012:5:289.

43. Weill M, Chandre F, Cécile B, Manguin S, Akogbeto M, Pasteur N, et al. The $k d r$ mutation occurs in the mopti form of Anopheles gambiae s.s. through introgression. Insect Mol Biol. 2000;9:451-5.

44. Diabate A, Brengues C, Baldet T, Dabire KR, Hougard JM, Akogbeto M, et al. The spread of the Leu-Phe kdr mutation through Anopheles gambiae complex in Burkina Faso: genetic introgression and de novo phenomena. Trop Med Int Health. 2004;9:1267-73.

45. Djègbè I, Boussari O, Sidick A, Martin T, Ranson H, Chandre F, et al. Dynamics of insecticide resistance in malaria vectors in Benin: first evidence of the presence of L1014S kdr mutation in Anopheles gambiae from West Africa. Malar J. 2011;10:261.

46. Reimer L, Fondjo E, Patchoké S, Diallo B, Lee Y, Ng A, et al. Relationship between $k d r$ mutation and resistance to pyrethroid and DDT insecticides in natural populations of Anopheles gambiae. J Med Entomol. 2008:45:260-6.

47. Ridl FC, Bass C, Torrez M, Govender D, Ramdeen V, Yellot L, et al. A preintervention study of malaria vector abundance in Rio Muni, Equatorial Guinea: their role in malaria transmission and the incidence of insecticide resistance alleles. Malar J. 2008;7:194.

48. Jones CM, Liyanapathirana M, Agossa FR, Weetman D, Ranson H, Donnelly $\mathrm{MJ}$, et al. Footprints of positive selection associated with a mutation (N1575Y) in the voltage-gated sodium channel of Anopheles gambiae. Proc Natl Acad Sci USA. 2012;109:6614-9.

49. Essandoh J, Yawson AE, Weetman D. Acetylcholinesterase (Ace-1) target site mutation 1195 is strongly diagnostic of carbamate and organophosphate resistance in Anopheles gambiaes.s. and Anopheles coluzzii across southern Ghana. Malar J. 2013;12:404.

50. Corbel V, N'Guessan R, Brengues C, Chandre F, Djogbenou L, Martin $T$, et al. Multiple insecticide resistance mechanisms in Anopheles gambiae and Culex quinquefasciatus from Benin, West Africa. Act Trop. 2007:101:207-16.

51. Wondji CS, Dabire R, Tukur Z, Irving H, Djouaka R, Djouaka J, et al. Identification and distribution of a GABA receptor mutation conferring dieldrin resistance in the malaria vector Anophelesfunestus in Africa. Insect Biochem Mol Biol. 2011;41:484-91.

\section{Publisher's Note}

Springer Nature remains neutral with regard to jurisdictional claims in published maps and institutional affiliations.

Ready to submit your research? Choose BMC and benefit from

- fast, convenient online submission

- thorough peer review by experienced researchers in your field

- rapid publication on acceptance

- support for research data, including large and complex data types

- gold Open Access which fosters wider collaboration and increased citations

- maximum visibility for your research: over $100 \mathrm{M}$ website views per year

At BMC, research is always in progress.

Learn more biomedcentral.com/submissions 